\title{
Silent Spring and The New York Times: How Rachel Carson Won the Journey
}

\author{
Kushal S. Shah, Indiana University Bloomington
}

\section{ABSTRACT}

This paper explores people's reception of and attitudes toward Rachel Carson's Silent Spring, originally published in 1962. Research was 1 conducted entirely through the lens of The New York Times (NYT) articles ranging from before the book's publication to the present. The articles vary heavily in perspective, representing a range of views towards Carson's vilification of both the pesticide industry and general American attitudes regarding environmental conservation. Articles from NYT represent public opinion well because the chosen articles come from views representing a variety of sources (corporations, scientists, book reviewers, historians, etc.) and perspectives ranging from maximum support to open criticism of the book. When observed over time, research into these articles tells the story of the change in acceptance of Silent Spring - how it has reached its current state of reverence and influence. This paper comprehensively examines a variety of articles regarding Silent Spring and America's environmental efforts, tracking the change of general attitudes over the 50 years since its publication.

\section{KEYWORDS: Silent Spring, public opinion, environmentalism, New York Times, newspaper archives}

\section{BACKGROUND}

Rarely is a book published that has the capability to revolutionize an industry, an entire nation, or even an entire way of thinking. Even for the ones that do, public memory is generally short-lived, causing the effects of such books to diminish rather rapidly over time. Rachel Carson's Silent Spring, however, has accomplished all of these feats since its publication in 1962. Her assertions about the potential dangers of pesticides (DDT in particular) and lack of environmental conservation remain applicable and impactful even in today's society. Carson's book now finds itself on the same list as Darwin's Origin of Species, Newton's Principia Mathematica, and Einstein's Meaning of Relativity as one of the top 50 books that changed the world (“50 Books", 2010). After, and even slightly before, its original release in September of 1962, multiple newspapers around the world responded to Silent Spring with countless views and perspectives. A particularly useful resource for understanding the reception of Silent Spring is The New York Times (NYT). Through the lens of articles published in NYT across the years since the book's publication, we gain insight into the evolution of views toward, and criticism of, Silent Spring.

Even before the publication of Carson's book, her ideas were met with mixed reactions from people in all fields. Though no one at the time could have predicted the book's future impact, it did create a lot of controversy, both positive and negative in the extremes. Climate change and environmental conservation, at this point in time, were two concepts that were known but not emphasized to nearly the level they are today.

\section{INITIAL REACTION}

The first mention of Silent Spring in The New York Times comes in an article on July 22nd, 1962, as a response to the pre-publication excerpts from Silent Spring in The New Yorker, written three months prior to the book's actual publication. Rather dramatic for a first article - the first of hundreds to come - it was released with the bold headlines, "Pesticides Industry Up in Arms Over a New Book" and "Rachel Carson Stirs Conflict - Producers are Crying 'Foul”, catapulting Carson into a sea of controversy from the outset (Lee, 1962). When viewed in retrospect, the audacious headlines prove that, even before the publication of Silent Spring, those who expected to be hurt by its vehement condemnation of DDT, other pesticides, and the chemical industry, were put on high alert and given further impetus to diminish the validity of Carson's views.

Just a month later, however, still prior to the book's 
publication, a second NYT article stated that Carson was "expected to appear on an hour-long 'CBS Reports' program that [would] examine her book," thereby swinging the pendulum in a completely different direction from that taken by the first article (Adams, 1962). This article began to establish Silent Spring as the subject of media attention, one of the initial building blocks of Silent Spring's publicity.

In the month leading up to the book's publication, over ten NYT articles and hundreds of outside ones were written, many quoting experts critical of the upcoming book, while others were quoted as voicing support for its resolute warnings. The Monsanto Chemical Company, as mentioned in one of these articles, was said to have published The Desolate Year, which envisioned the horrors of the U.S. going one year without pesticides ("Monsanto", 1962). This kind of reaction was typical of American chemical and agricultural corporations at the time, which were doing everything possible to destroy Carson's credibility even before her book's publication. But, on the other hand, some articles published at the time implicitly supported Carson's position. Coming from a seemingly unbiased source, one article claimed, "nothing in the field of conservation [had] provoked such an explosive response as Rachel Carson's [writing] about the irresponsible use of chemical sprays" (Atkinson, 1962). The combined influence of all the articles certainly helped get President Kennedy's attention, who soon thereafter reassured the American public that government agencies were examining the potentially dangerous, long-term side effects of widespread pesticide use (Hunter, 1962). With the White House taking action in reference to a book that had not even been published yet, Silent Spring was already set to be a groundbreaker.

Soon after publication, Carson's work drew widespread attention from all around the country, which became apparent in the explosion of NYT articles in the coming months. Predictably, the responses from drug manufacturers, foresters, gardeners, fruit growers, pesticide engineers, chemical corporations, etc. were of indignation and anger. Interestingly, however, after the first round of The New York Times articles, Carson herself was actually marginalized as a topic of discussion in subsequent ones, which, instead of directly attacking or supporting her, discussed and debated the real effects of DDT and other chemicals on the Earth. For example, an advertisement published in the newspaper in November referenced Carson and announced a roundtable discussion regarding pesticide use ("Radio", 1962). A later article that explained the results of a rather intricate study conducted on the consequences of chemical usage on agriculture stated that, even with the results of the experiment, "finding the hazards of pesticides was very difficult to assess," which in return spurred even more testing and conversation (Toth, 1962).

\section{SECOND WAVE}

After the critical first few months post-publication, The New York Times had a relatively dead period with very few articles regarding Silent Spring. During this time, debate and experiments still continued in the United States, but new findings and opinions were not surfacing at the same rate as before, causing a lack of 'news' on the subject. It must be reiterated that American public memory of front-page news has proven to be very short in the long run when viewed historically, and events that emphatically break ground are soon after forgotten without new catalysts to keep the issue on people's minds. Silent Spring, though it caused a storm of controversy when published, could have easily continued down this bleak path with time.

However, this changed in April 1963, when the discussion engendered by Silent Spring found a new catalyst. On April 3, the CBS Reports investigation entitled "The Silent Spring of Rachel Carson" was aired, in which Carson was pitted against Robert White-Stevens, a spokesman for the agricultural chemical industry. Carson presented herself calmly and reasonably, while White-Stevens came across as extreme with bold allegations against Carson's intentions. A major revelation from the show, as discussed in a NYT article the next day, was that the government lacked solid knowledge on "many of the issues that [Carson] had raised," which significantly bolstered her campaign 
(Gould, 1963). Infused with many supportive opinions from CBS's vast audience, Carson's cause gained new steam while reaching even greater heights in publicity. For the next year, the words 'Rachel Carson' and 'Silent Spring' served as trademark terms, almost always mentioned in NYT articles about the topic, even ones that did not directly relate to Carson or her book. Many articles at the time mentioned Carson's book and explained how actions were being taken to combat and investigate pesticide use across the spectrum, even at the government level, with headlines such as "Pesticides Inquiry Is Sought In House" and "U.S. Orders Study Of Two Pesticides" ("Pesticides", 1963; Toth, 1963). Nearly all articles in the year after the initial debate represented a positive outlook on Carson's book and focused on either Carson's subsequent work or new developments in the pesticide issue. The airing of Carson's CBS debate and the period thereafter became a critical factor for the breadth of Silent Spring's influence, with awareness of chemical dangers rising around the country, high-level discussions of scientific experiments and data increasing, and public opinion of Silent Spring skyrocketing in the book's favor.

\section{CARSON'S DEATH AND CONTINUED INFLUENCE}

Once Carson and her book's credibility were established, The New York Times continuously produced articles for many years that cited Carson, now ingrained as the face of the environmental movement. The articles fell into a general pattern: a major headline article about pesticide breakthroughs or high-level actions taken, with many smaller mentions in-between. A major illustration of this pattern began in November 1963 with a dynamic article that mentioned Carson's teachings and detailed charges leveled by the National Audubon Society at the U.S. Department of Agriculture, which was said to be "more interested in helping to sell pesticide and chemicals than in protecting the consumer's rights and welfare" (Devlin, 1963). As was shown by the article, Carson's reputation had grown to a point where her mention in an article was oftentimes used to simply gain credibility for the writing. Articles over the next few months were less focused on Carson's science than on other events in connection with her, such as her acceptance of the Audubon Medal and induction into the American Academy of Arts and Letters.

Less than two years after Silent Spring's publication, American readers were shocked by a new, front-page headline with the chilling words "Rachel Carson Dies of Cancer; 'Silent Spring' Author was 56" ("Rachel", 1964). The article described her life, important works, and overall effect on the environmental movement ("Rachel", 1964). A multitude of articles in the following weeks contained tributes to Carson, and news of her death further publicized the campaign that she had brought to the forefront of American media and politics. In the years afterwards, Carson and Silent Spring were mentioned at least monthly (and oftentimes more frequently) in NYT articles, as continual progress was made and real change was seen regarding America's pesticide situation. Almost all articles discussing the campaign to ban DDT - which gained ground a few years after Carson's death - mentioned her research at some point. A 1966 article entitled "New 'Silent Spring'?" linked the pesticide controversy to a new issue regarding "the practice of routinely including antibiotics in animal feed," the first sign of Silent Spring being adapted and referenced to bring change regarding new, related issues ("New", 1966). Articles about the actions and new developments in the pesticide fight continued to be written, but now Carson's name began to be used in articles regarding separate new environmental issues as well.

In the years around and after 1970, Silent Spring's direct influence became evident in the growing campaign against DDT, a topic on which more and more articles were being written. NYT authors focused on how a DDT ban had slipped through Carson's initial scathing indictment of pesticides - although public opinion of DDT had already crumbled because of her work - and how this was no longer possible (Brody, 1969). Two themes from this time period are apparent: the beginning of 'Since Rachel Carson...' types of articles which remembered her efforts and where they had taken America, and the strengthening of 'Ban DDT' 
types of articles that also mentioned the importance of Carson's crusade. In 1972, E.W. Kenworthy, a NYT journalist who had been with The New York Times for over 30 years, released a breakthrough article with the electrifying headline, "DDT Banned In US” (Kenworthy, 1972). The Environmental Protection Agency (EPA) had outlawed DDT, and Kenworthy sanctified Carson as the reason for America's environmental progress. When the court later backed the EPA's decision, Carson was once again revered in NYT articles, seen finally as the winner of the struggle she had rightfully brought up ten years ago.

With the pesticide battle appearing to have reached a conclusion, articles over the next few decades focused on new environmental struggles, although they continually pointed to Carson as an agent of inspiration for progress in a number of different areas. In a changed world in which environmental conservation had become a key, pressing issue, Carson remained idolized as one of the prime thought leaders of the movement. An NYT editorial regarding conservation of aquatic life posed a simple question: "Does Rachel Carson's 'Silent Spring' have to be rewritten each time our marine environment is threatened?" (Zawyrucha, 1977). The question demonstrates a new mentality among conservationists - that, having seen Carson's positive impact and the struggle she went through to get there, Americans should now come together more readily to enact positive change without having to fight through such a long conflict. Phrases such as 'ever since Rachel Carson sounded the alarm...' and 'because of the landmark work, Silent Spring' became indicative of the respect with which Rachel Carson was viewed. Articles about the structuring of new movements around Carson's ideals became common, and still remain common in more recent articles, such as a key one from 2006 discussing how Al Gore's An Inconvenient Truth campaign relates to Carson's initial 1960's campaign that ignited the entire movement (Kakutani, 2006). Similar articles were written throughout the decade, leading up the September 2012, 50th anniversary of Silent Spring, in which the book once again sparked a large number of articles written over the month. Carson is often still referenced, alluded to, and respected in today's society, as displayed by recent NYT articles.

\section{CONCLUSION}

A thorough analysis of The New York Times articles ranging from the early 1960's to present time allows for an astounding, objective understanding of Silent Spring's battle through time - the actions, reactions, and impacts of the revolution it began. Responses to Carson's masterpiece were initially strong and mixed, but after Silent Spring wreaked havoc on mainstream thought processes of the 1960's while maintaining its credibility, the book entered the steady stream of environmental progress up to this day, albeit with bumps along the way. Carson's assertions echo back and forth to this day, remaining durable and adaptable through the evolution of responses to her book and evolution of public opinion towards the environmental movement that has occurred over the last half-century. Through a change-over-time analysis of NYT articles, it is possible to understand exactly how Silent Spring achieved everything that it did. Carson's message emerged in a world in which environmental conservation was just beginning to be a concern. It has come to fruition in a world in which the discussion of climate change takes place vigorously and on a global basis.

\section{REFERENCES}

50 books that changed the world (2010, January 26). Open education database. Retrieved from: http://oedb.org/ilibrarian/50_books_ that_changed_the_world/

Adams, V. (1962, August 30). CBS Reports plans a show on Rachel Carson's new book. The New York Times, p. 42.

Atkinson, B. (1962, September 11). Rachel Carson's articles on the danger of chemical sprays prove effective. The New York Times, p. 30 .

Brody, J.E. (1969, April 30). Attacks on use of DDT increasing. The New York Times, p. 42.

Devlin, J.C. (1963, November 9). US is assailed over pesticides. The New York Times, p. 50.

Gould, J. (1963, April 4). TV: Controversy over pesticide danger weighed. The New York Times, p. 95.

Hunter, M. (1962, August 31). US sets up panel to review the side effects of pesticides. The New York Times, p. 9. 
Kakutani, M. (2006, May 23). On global warming, with passionate warnings and pictures. The New York Times, p. E6.

Kenworthy, E.W. (1972, June 15). DDT banned in US almost totally, effective Dec. 31st. The New York Times, p. 1.

Lee, J.M. (1962, July 22). 'Silent Spring' is now noisy summer; pesticides industry up in arms over a new book. The New York Times, p. 87.

Monsanto dissects pesticide criticism: Monsanto joins pesticides issue (1962, September 22).. The New York Times, p. 28.

New 'Silent Spring'? (1966, August 12). The New York Times, p. 30.

Pesticides inquiry is sought in House (1963, May 3). The New York Times, p. 18.

Rachel Carson dies of cancer; 'Silent Spring' author was 56 (1964, April 15). The New York Times, p. 1.

Radio (1962, November 28). The New York Times, p. 79.

Toth, R.C. (1962, December 7) Pesticides study found difficult: US panel trying to assess chemical perils to body, but the facts are few. The New York Times, p. 41.

Toth, R.C. (1963, May 5). U.S. orders study of two pesticides. The New York Times, p. 76.

Zawyrucha, T.S. (1977, April 17). ...to avoid a Silent Spring. The New York Times, p. LI32. 